\title{
Solving manufacturing problems - From here on or with an eye looking in the rear-view mirror?
}

\author{
M. Aniander \\ Industrial Economics and Management (Indek) \\ Royal Institute of Technology, KTH \\ SE-100 44 Stockholm, Sweden, \\ +4687906751(telephone) +4687906741 (fax) \\ aniander@lector.kth.se
}

\begin{abstract}
Methods used for improving the efficiency of manufacturing very seldom recognize the importance of the facility or company history when approaching a problem. In this paper a plant of a large Swedish manufacturer of doorsets is used to show that strategic management consists of not only understanding preceding events, or the history, but also understanding the context, influencing contextual factors as well as influencing what is percieved as context. The context consists of market(s), competitors, suppliers and, as is evident in this case, the company group to which the plant belongs.
\end{abstract}

\section{Keywords}

Manufacturing, production, batches, process layout, product layout, contextual factors, company group, history 


\section{INTRODUCTION}

Literature or papers concerning production, e g facility location, facility layouts, planning etc, very seldom take the facility or company history into account when discussing solutions to production problems. In order to find good solutions it is vital to have a profound understanding of the manufacturing at hand. In this paper a case study is used in order to show that such an understanding requires an understanding of preceding events, or the history, as well as an understanding of the context.

Swedoor is a large Swedish manufacturer of doorsets. In Forserum, in southern Sweden, they have a plant making high performance doorsets, i e doorsets that provide sound protection and fire resistance. In 1994 the production management reorganised the factory layout, which meant that the paced production lines were replaced with a layout where machines were arranged according to their function, a traditional process layout. The paced lines were too rigid and could not respond to changes in the product mix. However, at the time, a process layout seemed as a somewhat old-fashioned way of organising the production. The case study is aimed at describing the reorganisation, trying to understand the underlying reasons as well as understanding the effects of it.

\section{THE STARTING POINT}

\subsection{A door's route through the plant}

The production process starts with the core. The core typically consists of a fibre board with a frame of softwood. Tha main surfaces have a hardboard substrate on which the surface finish is attached. The surface can be painted, veneered or laminated.

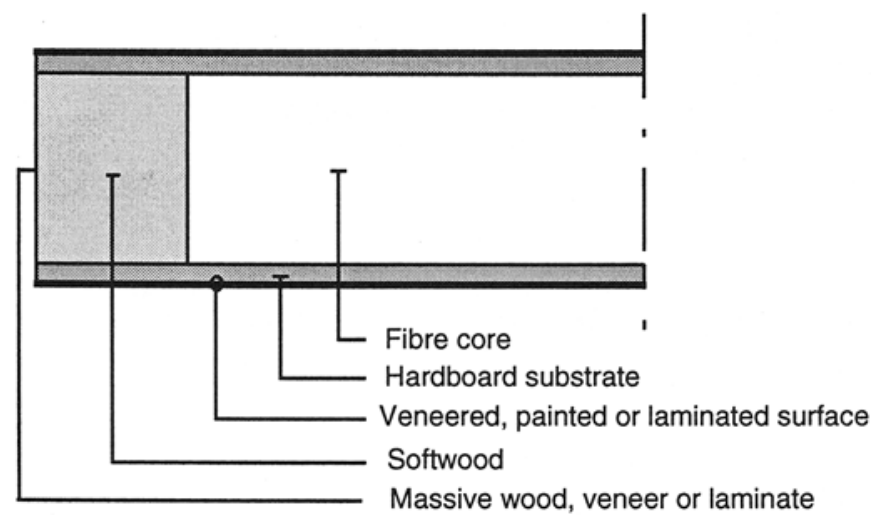

Figure 1 Cross section of door leaf. 
After this the door is completed through a series of processes. When the case study was inititated parts of this was organised in five different, paced lines, used for different kinds of doors. The B line was used for standard doors with a thickness of $40 \mathrm{~mm}$ and the $\mathrm{C}$ line for standard doors with $64 \mathrm{~mm}$ thickness. The $\mathrm{P}$ line was used for doors with laminated surface, the $\mathrm{S}$ line for security doors (with a steel sheet between the fibre core and the hardboard substrate) and the A line for customised, oversized doors.

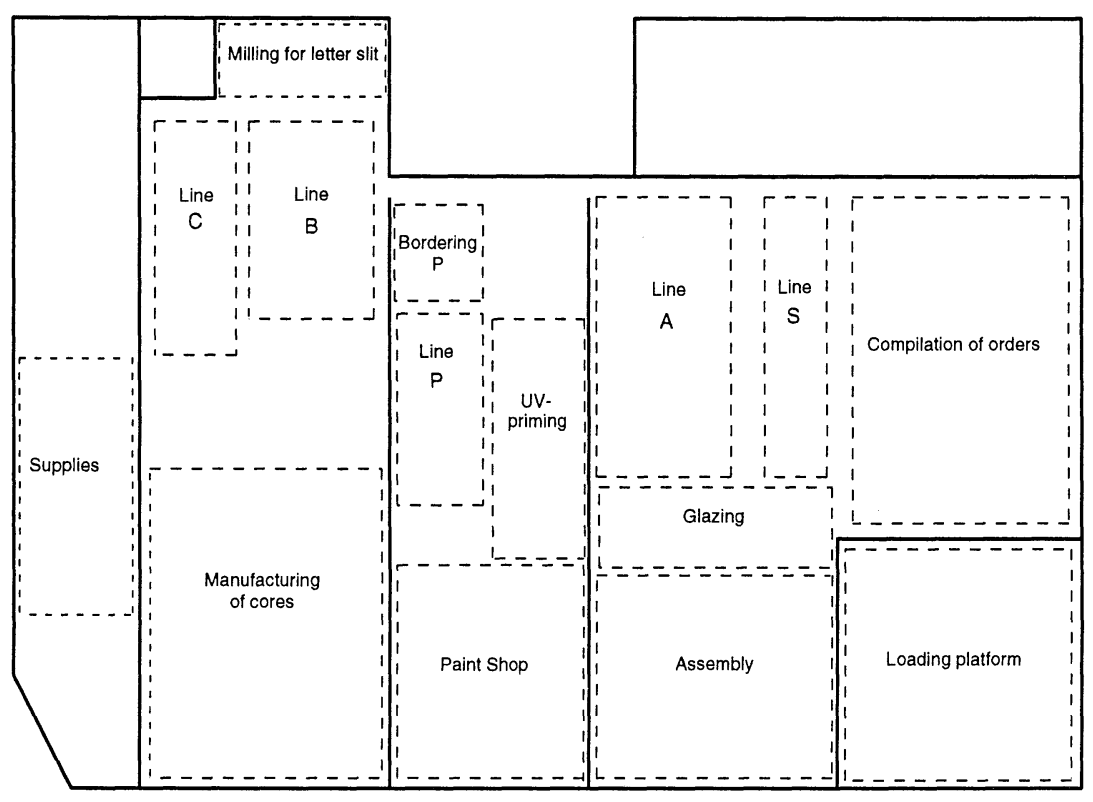

Figure 2 Layout of the Forserum plant before changes.

To prepare for letter slits, the next process is milling. Doors supposed to be painted are subsequently given a layer of UV-hardened primer before entering the paint shop. The door is completed after prospective glazing is added and the iron mongery has been assembled.

\subsection{Drawbacks with the original layout}

During the beginning of the 1990s there were changes in the demand for high performance doorsets. The demand for laminated doors grew rapidly on the expense of veneered and painted doors. Although the plant in Forserum had the overall capacity to meet the demand for high performance doorsets, the capacity for making laminated doors were lower than the demand. 
Laminated doorsets could only be processed through the P line. Individual machines in other door lines could be used for laminated doors, but no other line could be utilised, as a paced line, for making laminated doors. In order to meet the demand for laminated doors all resources had to be used, even if it implied manual feeding of machines connected with a conveyor belt.

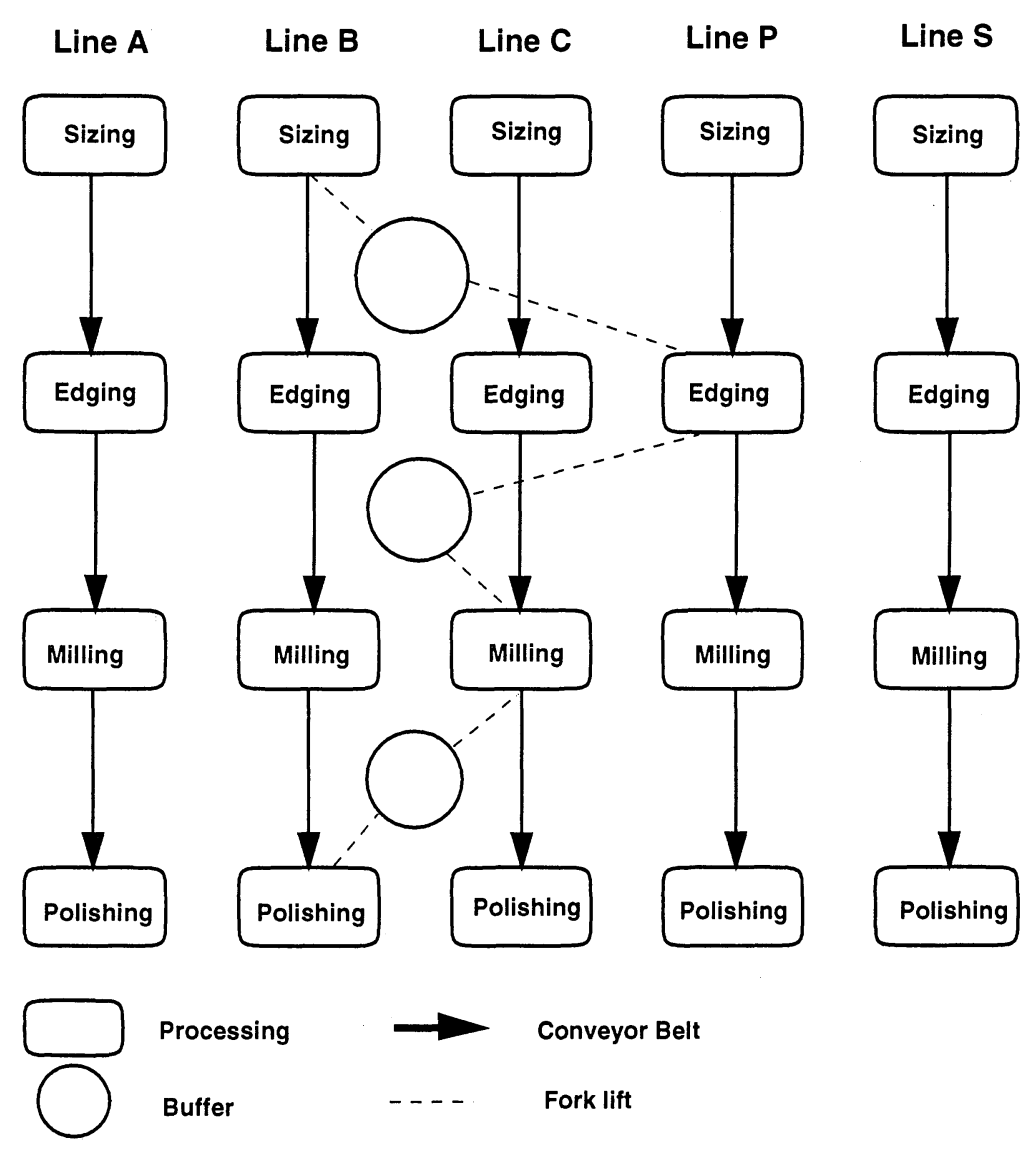

Figure 3 Laminated doors were manually handled and processed by machines in different door lines. 


\section{THE NEW LAYOUT}

In 1993 the recession in Sweden had a dramatic impact on the demand for building components. The overall volumes dropped by $20 \%$. The construction of new houses was almost wiped out, leaving Swedoor with the demand originating mainly from restoration, reconstruction and extensions. This meant that an average work order decreased from 100 doorsets to just under three! The number of setups increased accordingly and left the paced door lines ill-placed.

In 1994 the work began on discarding the paced door lines ande replacing them with a traditional process layout. The term, or even the concept of process layout, was never mentioned. The new layout was rather referred to as a means of improving the flow of products inside the plant, as if it was a product layout.

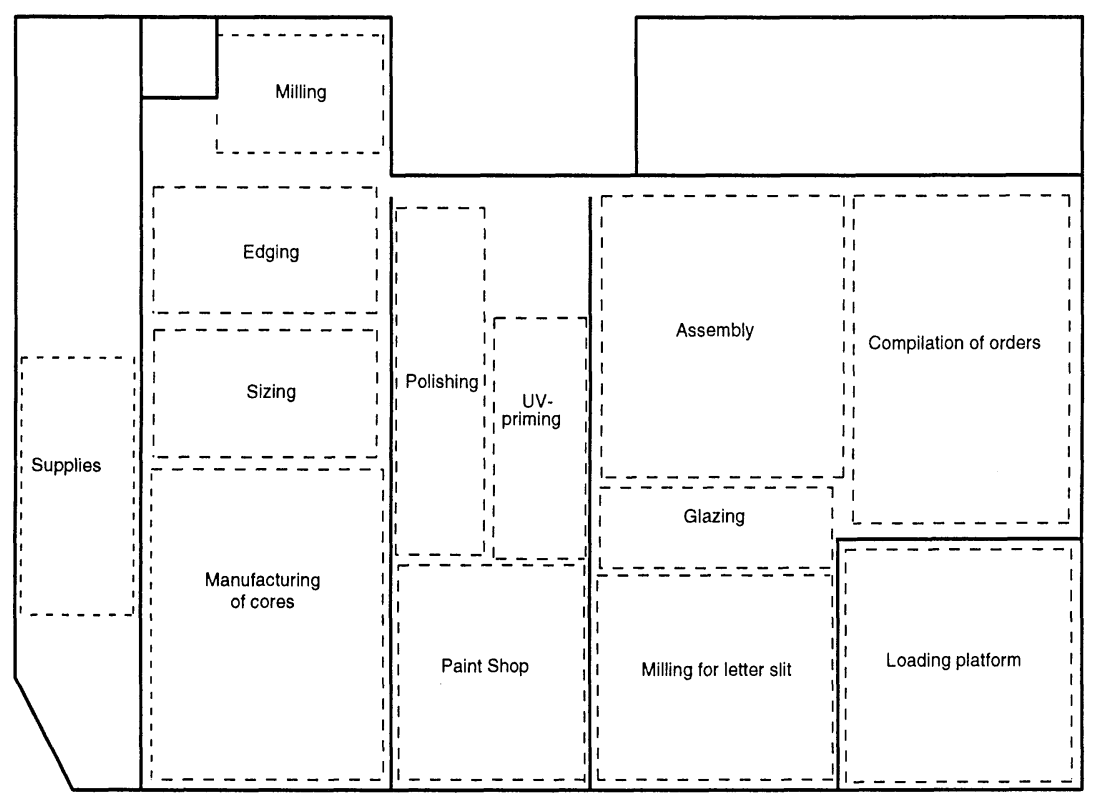

Figure 4 The new layout in the Forserum plant.

Typically, a process layout is described as a layout where similar processes are located together, see e g Slack (1998). A product layout is described as a layout where the design of the product govern the location of the processes. The design, or rather the similarity between the different designs of doors in this case, made it quite sensible to describe the layout as a product layout. Every operation is not performed on every door, but every door has the operations in the same sequence 
and thus follows the same route through the plant. The reorganisation thus meant that the rigid paced lines were replaced with a process layout, that, owing to the similarity between the different doors, worked as though it was a product layout.

However, planning of manufacturing regards the different processes as different work centers. In the order scheduling, every work center is assigned with a specific point in time when processing of an order has to be completed. This means that the throughput time assumes the value of a process rather than a product layout. Unless the move time between different processes is significant, it seems that the planning principle is more relevant than the physical layout when describing the working mode of a plant.

\section{PREVIOUS CHANGES}

In 1972 the plant in Forserum was bought by Svenska Tändsticksbolaget (Swedish Match). Previously, it had been a family owned business, making almost every kind of doorsets. The company group now moved manufacturing between different plants, making each of them the main manufacturer of certain kind of doors. The plant in Forserum was made the main supplier of high performance doorsets. Manufacturing of other products were moved or discontinued, leaving the Forserum plant as a plant specialized in high performance doorsets.

High performance doorsets are made in significally smaller batches, many more variants etc, than internal doorsets used in homes. Thus, the prerequisites for the reorganisation, i e small batches, variances in product mix etc, were at hand as early as in the mid seventies. Thus, rather than be doubtful of changing to a process layout, it should be called in question why the reorganisation had not occurred earlier.

In order to understand this we need to look at what happened earlier in the plant. In the beginning of the sixties, the manufacturing facility was a small independent, family owned company, that made all prefabricated building-units one could think of. During 1965 - 1974 there was a large public programme in Sweden, called Miljonprogrammet, see e g Eriksson (1994). The purpose was to build 1 million housings in ten years. All companies making building components grew rapidly during this period of time. At the end of this period the facility in Forserum was a plant specialised in making doorsets that co-operated with other companies in a joint marketing company. The demand grew so rapidly that the plant in Forserum met every increase with a new, specialised paced line.

When the public programme was completed, the building activities rapidly decreased. As described above, the group reorganised, moving production between different facilities, thus leaving the plant in Forserum responsible for producing high performance doorsets. The plant inherited the paced lines from the earlier production. Paced lines, typically assembly lines in car manufacturing, where such 
a powerful model for manufacturing that the efficiency of the door lines wasn't questioned until the late 1980s.

\section{APPROACHING THE END FOR THE DOOR LINES}

At the end of the 1980s people in Forserum started to question the efficiency of the plant. During much of the eighties the plant had fallen into decay since the investments in new production equipment had been put to a minimum. In 1987 Swedish Match was bought by Stora, a large swedish company, with it's main business in pulp and paper production. In order to raise the profitability of making building components a large investment program started.

The manufacturing of door cores was altered. Previously cores had been made more or less manually. Now a semi-automatic cell for core making was built. In the paint shop the paint boxes were replaced with a conveyor system, transporting door leafs passed painting robots.

In 1990 Stora bought the german pulp and paper company Feldmühle. Burdened by the interest charges payed on the purchase sum Stora focused on cash flow rather than profitability. The plant in Forserum had to halt it's investments since corporate management demanded that the plant should generate a positive cash flow. Since the plant had a very low profitability this meant that the investments had to be smaller than the depreciation on equipment. Finally, the tight limits on investments, together with changes in the product structures, initiated in the early 1970s, and changes in demand,originated in the early 1990s, led to a solution where the paced lines were replaced with a process layout. There were no new machines bought, the new layout simply consisted of relocated machines.

\section{CONCLUSIONS}

In order to find good solutions to production problems it is vital to understand the context in which the problem is embedded (for a more thorough discussion of this see Aniander and Blomgren (1997)). This concerns previous events, e g the so called Miljonprogrammet is a matter of vital importance when describing swedish companies making building components. As have been showned in this paper it is also important to understand the organisational context. Much of the circumstances that has influenced the manufacturing facility in Forserum are connected to the corporate context of the business group.

Owing to different organisational demands the goals for the plant in Forserum have changed. This involves manufacturing of different products depending on the business concept, focusing on profitability or cash flow depending on the demands stated by corporate management etc. This could be described as means-ends chains. Goals on one level are divided into sub-goals on the next level, thus forming a 
goal-hierarchy, March and Simon (1958). From the higher level the sub-goals tend to be viewed as means to achieve the goal. When top management finds new means to achive their goal, the production management finds their goal changed, leaving them uncertain on what they are supposed to achieve and uncertain on their means.

A manufacturing facility must be in harmony with its context. The context consists among other things of the market(s), competitors, suppliers etc. From a perspective from within manufacturing, this case study clearly shows that the organisational setting, in this case the company group, is an important part of the context (for a discussion of the importance of different perspectives see Danielsson (1983)). Actions at the group level often affects the Forserum plant, directly as well as indirectly, since such actions often affects what or who are considered to be market(s), competitors, suppliers etc. Strategic management thus consists of understanding the context, influencing contextual factors as well as influencing what is perceived as context. This must be done with a deep understanding of the manufacturing processes if harmony is to be achieved, since very few operations can be treated without consideringthe restrictions of existing facilities. To reach such an understanding, traditional descriptions of manufacturing must be complemented with studies where changes or solutions to production problems are seen as a set of activities with its own history.

\section{REFERENCES}

Aniander, M. and Blomgren, H. (1997) Industrial Production - a way of describing, analysing and solving production problems, in Proceedings, from The Sixth International Conference on Management of Technology, MOT 1997, IAMOT.

Danielsson, A. (1983) Företagsekonomi - en översikt (in Swedish), Studentlitteratur, Lund

Eriksson, O. (1994) Byggbeställare i brytningstid (in Swedish), Byggforskningsrådet, Stockholm.

March, J. G. and Simon, H. A. (1958) Organizations, John Wiley, New York. Slack, N. et al (1998) Operations Management, Pitman Publishing, London. 